\title{
CCAAT enhancer-binding proteins have long boney fingers
}

\author{
Friedrich C. Luft
}

Published online: 10 December 2011

(C) Springer-Verlag 2011

The giant-cell tumor of bone (GCT) is a relatively uncommon benign bone tumor, characterized by the presence of multinucleated giant osteoclast-like cells $[1,2]$. In most patients with GCT, the tumors develop gradually; however, they may recur locally in as many as $50 \%$ of cases. GCT account for about $5 \%$ of primary bone tumors and about $20 \%$ of benign bone tumors in general. In China and other parts of Asia, GCT are decidedly more common [3]. About $5 \%$ of GCT patients harbor a malignant tumor and develop metastasis [3].

CCAAT enhancer-binding proteins (or C/EBPs) are a family of transcription factors consisting of six members, $\mathrm{C} / \mathrm{EBP} \alpha$ to $\mathrm{C} / \mathrm{EBP} \zeta$ [4]. C/EBP proteins exhibit highly conserved basic leucine zipper domains. The different members of C/EBP family form homodimers, heterodimers with another form of the C/EBPs, and with other transcription factors. Dimerization is required for C/EBPs to bind specifically to DNA through a palindromic sequence in the major groove of the DNA [5]. The C/EBP proteins also contain activation and regulatory domains that, once bound to DNA may recruit cofactors to remodel and open up chromatin structure and/or recruit basal transcription factors. C/EBPs are found in hepatocytes, adipocytes, hematopoietic cells, spleen, kidney, brain, and many others organs. C/EBP proteins are involved in different cellular responses, such as cellular proliferation, growth, differentiation, metabolism, immunology, and as we learn here, bone regulation.

F. C. Luft $(\bowtie)$

Experimental and Clinical Research Center, Charité Medical Faculty and Max-Delbrück Center for Molecular Medicine,

Lindenbergerweg 80 ,

13125 Berlin, Germany

e-mail: luft@charite.de
Osteoclasts are bone cells that resorb bone tissue by dissolving its mineralized matrix and breaking up the organic bone. Kolliker discovered osteoclasts 1873 [6]; however, their activity has only recently been elucidated. Osteoclasts are formed from monocytes [7]. Their formation requires the presence of the nuclear factor $\mathrm{KB}(\mathrm{NF}-\mathrm{kB})$ receptor activator (RANK), the receptor's ligand (RANKL), and macrophage colony-stimulating factor (M-CSF). Neighboring stromal cells and osteoblasts produce these membrane proteins, thus requiring direct contact between these cells and osteoclast precursors. M-CSF acts through its receptor the osteoclast colony-stimulating factor 1 receptor (c-fms), a transmembrane tyrosine kinase receptor, leading to secondary messenger activation of the tyrosine kinase Src. Both molecules are necessary for osteoclastogenesis and are widely involved in the differentiation of monocyte/macrophage-derived cells. RANKL is a member of the tumor necrosis factor family of proteins and is essential in osteoclastogenesis. RANKL activates NF- $\mathrm{KB}$ and nuclear factor of activated $\mathrm{T}$ cells (NFATc1) by activating RANK. Osteoclast differentiation is inhibited by osteoprotegerin, which is produced by osteoblasts and binds to RANKL thereby preventing interaction with RANK.

Smink et al. [8] now show that $\mathrm{C} / \mathrm{EBP} \beta$ is a determinant of giant osteoclast formation in GCT and that a pharmacological treatment for GCT could possibly be applied to inhibit tumor growth. How can we tie these components together? The answers follow years of effort from the Leutz laboratory [9-13]. The story begins with their elucidation of how translational control of $\mathrm{C} / \mathrm{EBP} \beta$ isoforms is regulated. From a common C/EBP $\beta$ mRNA, small upstream openreading frames (uORF) mediate translational control and thereby regulate the expression of long and truncated protein isoforms, as shown for $\mathrm{C} / \mathrm{EBP} \beta$ in Fig. 1. C/EBP $\beta$ mRNA translates into two long protein isoforms known as 

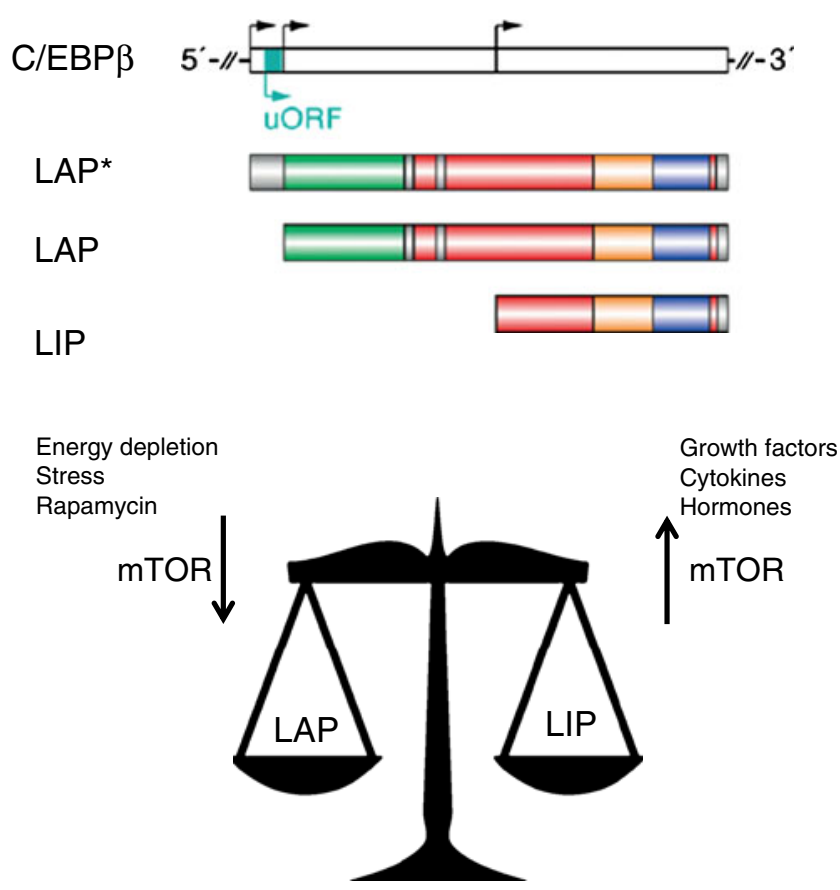

Fig. $1 \mathrm{C} / \mathrm{EBP} \beta$ mRNA (open bar) contains a small upstream openreading frame $(u O R F)$ that precedes the initiation condon. The uORF regulates the balanced expression of long $\left(L A P^{*}\right.$ and $\left.L A P\right)$ or truncated $(L I P)$ form of $\mathrm{C} / \mathrm{EBP} \beta$. The two isoforms have distinctly different functions (from [10])

liver-activating protein (LAP and LAP*) and the truncated liver inhibitory protein (LIP). The pathway that determines whether C/EBP $\beta$ mRNA makes LAP or LIP is mammalian target of rapamycin (mTOR). mTOR is a serine/threonine protein kinase that belongs to the phosphatidylinositol 3-kinase-related kinase protein family. The pathway functions as a nutrient energy/redox sensor and regulates cell growth, cell proliferation, cell motility, cell survival, protein synthesis, transcription, and as we see here, also translation. The Leutz laboratory has recently reviewed the mechanisms how uORF regulate $\mathrm{C} / \mathrm{EBP} \beta$ mRNA isoform production [10]. Under the influence of mTOR activation, C/EBP $\beta$ mRNA produces more LIP and less LAP. The LIP isoform is commonly expressed in cancers, such as Hodgkin's disease, anaplastic large-cell lymphoma, breast cancer, and as shown by Smink et al. here, in GCT [8]. The drug rapamycin (generic name sirolimus) inhibits mTOR and therefore can steer C/EBP $\beta$ mRNA into making LAP, rather than LIP.

Smink et al. showed earlier how $\mathrm{C} / \mathrm{EBP} \beta$ differentially affects bone mass [11]. The group found that rapamycin inhibited osteoclast generation from monocyte precursors in wild-type mice. They then used C/EBP $\beta$ gene-deleted mice to show that osteoclast precursors in these mice were not influenced by rapamycin. The C/EBP $\beta$ gene-deleted mice also exhibited increased bone reabsorption because of dysregulated osteoclast activity. Furthermore, the V-maf musculoaponeurotic fibrosarcoma oncogene homolog B
(MafB) transcription factor was downregulated in these mice. The group then found that expression of the LAP and LIP isoforms in monocytes differentially affected MafB promoter activity. Their data revealed that the $\mathrm{C} / \mathrm{EBP} \beta$ LIP isoform downregulates MafB gene expression, while the LAP isoform enhanced MafB expression. Moreover, ectopic expression in monocytes of either LAP or LIP $\mathrm{C} / \mathrm{EBP} \beta$ isoforms dramatically affected osteoclastogenesis and "knock in" mice that expressed only the LAP or the LIP isoforms instead of the wild-type C/EBP $\beta$ gene had tiny or massively enlarged osteoclasts in their bones, respectively $[11,12]$. We can imagine a schema in which monocyte precursors are transformed to osteoclasts largely through the C/EBP $\beta$ LIP isoform via attenuation of MafB. mTOR pathway activity modulates this process, as shown in Fig. 2.

In the current report, Smink et al. [8] suggest that clinical utility can be derived from their findings, particularly for patients with GCT. Inhibition of mTOR signaling has become standard practice in transplantation medicine and is also used in the treatment of various malignancies, notably renal cell carcinoma. Another more common bone disease that comes to mind is Paget's disease of bone (PDB). Histologically, the primary affected cells in PDB are osteoclasts that are numerous, enlarged, hypermultinucleated, and hyperactive probably because of RANKL hypersensitivity [14]. A downside could be the inhibition of normal bone growth and turnover by mTOR inhibition. Alvarez-Garcia et al. [15] investigated the effects of rapamycin on longitudinal bone growth. They gave 4-week-old rats rapamycin daily for 2 weeks. Rapamycin-treated rats were growth retarded and had marked alterations in their growth plates, compared to controls. Interestingly, osteoclasts were reduced,

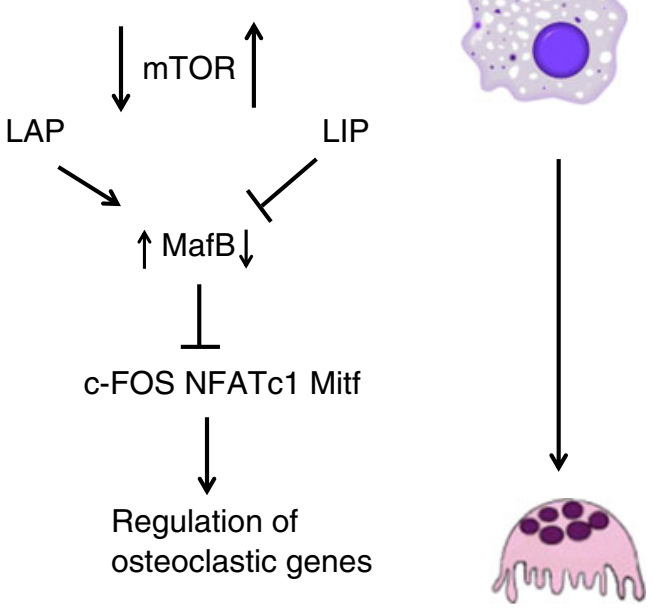

Fig. 2 Rapamycin inhibits mTOR, which increases expression of LAP. LAP induces expression of MafB. MafB inhibits NFATc1 and other osteoclastic transcriptional regulators, such as c-Fos and Mitf. Their inhibition results in the downregulation of osteoclastic genes (from [11]) 
particularly near to the chondroosseus junctions. However, also conceivable would be the concomitant administration of an mTOR inhibitor along with denosumab, a human monoclonal antibody with high affinity to RANKL, which would inhibit RANK signaling. In that way, toxicity from mTOR inhibition could be held to a minimum. Translating basic findings to clinical medicine is never easy, but understanding mechanisms is always the first step.

Respectfully,

Friedrich C. Luft

\section{References}

1. Wülling M, Engels C, Jesse N, Werner M, Delling G, Kaiser E (2001) The nature of giant cell tumor of bone. J Cancer Res Clin Oncol 127:467-474

2. Wuelling M, Delling G, Kaiser E (2003) The origin of the neoplastic stromal cell in giant cell tumor of bone. Hum Pathol 34:983-993

3. Thomas DM, Skubitz KM (2009) Giant cell tumour of bone. Curr Opin Oncol 21:338-344

4. Ramji DP, Foka P (2002) CCAAT/enhancer-binding proteins: structure, function and regulation. Biochem J 365:561-575

5. Kovács KA, Steinmann M, Magistretti PJ, Halfon O, Cardinaux JR (2003) CCAAT/enhancer-binding protein family members recruit the coactivator CREB-binding protein and trigger its phosphorylation. J Biol Chem 278:36959-36965
6. Nijweidi PJ, Burger EH, Feyen JH (1986) Cells of bone: proliferation, differentiation, and hormonal regulation. Physiol Rev 66:855-856

7. Schoppet M, Preissner KT, Hofbauer LC (2002) RANK ligand and osteoprotegerin: paracrine regulators of bone metabolism and vascular function. Arterioscler Thromb Vasc Biol 22:549-553

8. Smink JJ, Tunn P-U, Leutz A (2011) Rapamycin inhibits osteoclast formation in giant cell tumor of bone. J Mol Med (in press)

9. Calkhoven CF, Muller C, Leutz A (2000) Translational control of $\mathrm{C} / \mathrm{EBP}$ alpha and C/EBPbeta isoform expression. Genes Dev 14:1920-1932

10. Wethmar K, Smink JJ, Leutz A (2010) Upstream open reading frames: molecular switches in (patho)physiology. Bioessays 32:885-893

11. Smink JJ, Begay V, Schoenmaker T, Sterneck E, de Vries TJ, Leutz A (2009) Transcription factor C/EBPbeta isoform ratio regulates osteoclastogenesis through MafB. EMBO J 28:1769-1781

12. Wethmar K, Bégay V, Smink JJ, Zaragoza K, Wiesenthal V, Körken B, Calkhoven CF, Leutz A (2010) C/EBP $\beta^{\triangle \mathrm{uORF}}$ micea genetic model for uORF-mediated translational control in mammals. Genes Dev 24:15-20

13. Smink JJ, Leutz A (2010) Rapamycin and the transcription factor $\mathrm{C} / \mathrm{EBPbeta}$ as a switch in osteoclast differentiation: implications for lytic bone diseases. J Mol Med 88:227-233

14. Chung PYJ, van Hul W (2011) Paget's disease of bone: evidence for complex pathogenetic interactions. Semin Arthritis Rheum (in press)

15. Alvarez-García O, García-López E, Loredo V, Gil-Peña H, Rodríguez-Suárez J, Ordóñez FA, Carbajo-Pérez E, Santos F (2010) Rapamycin induces growth retardation by disrupting angiogenesis in the growth plate. Kidney Int 78:561-568 